\title{
A APLICAÇÃO ADEQUADA DA TEORIA DA JANELA QUEBRADA NO BRASIL
}

\author{
Deise dos Santos dias da Silva, Pablo Rodrigo França
}

Universidade do Oeste Paulista - UNOESTE, curso de Direito, Presidente Prudente, SP. Email: p.r.franca@hotmail.com

\section{RESUMO}

A segurança sempre teve destaque entre os itens de preocupação da população brasileira. Contudo, a importância cresceu fruto do também vertiginoso aumento da violência. A sensação de impunidade é, sem dúvidas, fator causal notabilizado. Vislumbra-se que a ausência do Estado em ações preventivas ou repressivas, sobretudo nas delinquências menores, seja por abandono no combate ou exegese de que o ato não possui importante lesão ao bem jurídico, induz e instiga a prática reiterada de desordem que, em médio prazo, conduz a ações cada vez mais graves e que fomentam a nefasta sensação de impunidade e insegurança que tanto tem afligido a sociedade e obrigando o cidadão ao próprio encarceramento. Assim, pareceu oportuno considerar um novo método de abordagem da segurança pública exaltando o estudo da broken windows theory. Com base nesta, adequando a nossa realidade, discute-se a possibilidade concreta de redução gradativa dos índices de violência.

Palavras-chave: Janela quebrada, impunidade, dignidade humana, delitos menores.

\section{THE APPROPRIATE APPLICATION OF THE THEORY OF BROKEN WINDOW IN BRAZIL}

\begin{abstract}
Safety has always stood out among the items of concern of the Brazilian population. However, the importance grew as a result of the soaring violence. The feeling of impunity is, without doubt, a notable causal factor. It is envisaged that the absence of the State in preventive or repressive actions, especially in minor delinquencies, whether by abandonment in the combat or exegesis that the act does not have an important injury to the legal good, induces and instigates the repeated practice of disorder that, on average Lead to increasingly serious actions that foment the harmful sensation of impunity and insecurity that has so much afflicted the society and obliging the citizen to the own incarceration. Thus, it seemed opportune to consider a new method of approaching public safety by highlighting the study of broken windows theory. Based on this, adapting our reality, we discuss the concrete possibility of a gradual reduction of violence rates.
\end{abstract}

Keywords: Broken window, impunity, human dignity, misdemeanors.

\section{INTRODUÇÃO}

O núcleo desta pesquisa teve como tema a violência e é norteado por dezenas de normas consagradas na Constituição Federal. Destacamos os artigos 5ㅇ e 6ㅇ por bem demonstrar que a segurança pública e a paz urbana, condutores da real liberdade, são fundamentais ao bem estar do cidadão.

O legislador estabeleceu inúmeras garantias pétreas com o objetivo do amplo crescimento do cidadão. A garantia da segurança e afastamento da violência são assuntos que afrontam a qualquer outro direito fundamental, pois, a vida consagrada como substancial não é apenas a de simples existência, mas é essencialmente de existência digna, com o exercício de todos os demais direitos, notadamente pelo tema proposto, da segurança, liberdade de ir e vir, do direito social ao lazer e com igualdade ampla. Nada obstante a garantista e bem escrita Carta da República 
questiona se de fato tais direitos estão sendo exercidos de maneira absoluta por aqueles cidadãos que exercem suas vidas nos limites das regras traçadas pelo Estado Democrático de Direito.

Hodiernamente, especial nos grandes centros, são indiscutíveis e intoleráveis os índices de criminalidade que atingiram o Brasil, notadamente os violentos. Ainda, que os cidadãos cumpridores dos regramentos postos estão enclausurados em pequenos imóveis, cada vez mais cerrados, sem a liberdade modesta ou excluídos de condutas familiares socialmente necessárias à própria existência. A aparente desordem demonstrada pelos patrimônios deteriorados, mesmo que públicos, pichações, loteamento de calçadas comuns, jogos proibidos exibidos em calçadões, consumo de drogas a céu aberto, ruas usadas como latrinas, importunações a tranquilidade ou as mulheres em transportes coletivos, som exacerbado, consumidores excessivos de álcool, desrespeito aos direitos mínimos dos idosos, deficientes ou gestantes, seja ao estacionamento próximo a porta de entrada até a fila do estabelecimento bancário ou acento ao metrô, pequenos furtos de transeuntes ou lojas, enfim, uma série de condutas consideradas pequenas e já banalizadas pelos órgãos públicos, mas, que conduzem ao entendimento de abandono e desordem, sem a presença do Estado e de que o mal imperou impune. Pior, estudos e gestões já aplicadas em outro país demonstraram que a relação de causalidade entre a desordem e criminalidade é maior do que qualquer outro fator social. Ou seja, a desordem leva à criminalidade, assim como a tolerância com pequenos delitos e contravenções leva, inevitavelmente, à criminalidade violenta.

O momento é determinante de mudança de paradigma e premissas no combate a violência.

Assim, o presente estudo nos parece de absoluta essencialidade, com o objetivo ousado em, ao menos, chamar ao debate a discussão acadêmica quanto ao tema, sem o temor de hermenêutica equivocada ou segregadora, propiciando novos entendimentos e questionamentos para que, com análise crítica, uma possível busca do melhor ou mais adequado modelo de gestão possa ser encontrado, com o aperfeiçoamento do sistema e consagrando os direitos fundamentais na busca da almejada paz pública em uma sociedade fraterna.

\section{METODOLOGIA}

O presente trabalho foi realizado por meio de abordagens doutrinárias, legislações e artigos, inclusive eletrônicos. Aproveitou-se da experiência empírica do trabalho dos autores, seja na dedicação efetiva nas ações de segurança pública ou na prática desenvolvida em estágios, aplicando-se para tanto e de maneira principal, mas, não exclusiva, do método hipotéticodedutivo.

Conforme percebido foi buscada a discussão da realidade, elencando os paradigmas que devem ser rompidos, com informações explanadas dialeticamente, fundamentando uma sugestão ousada de novo modelo da gestão a ser aplicada em busca da consagração de todos os direitos, especialmente a paz pública e a segurança coletiva.

\section{RESULTADOS}

A relevância do tema é inquestionável, talvez, a real preocupação do cidadão entre os três maiores problemas sociais. A desordem aparentemente instalada e a sensação de abandono do Estado afugentou a população que passou a sobreviver aprisionada em sua própria residência. Os números estatísticos exibem com soberba a vitória do mal quando aponta o crescimento de todos os índices criminais, do mesmo modo que cai a confiança pelos órgãos constituídos para o combate. 
Cremos realmente na ineficiência do vigente modelo adotado pelo Estado aos órgãos de segurança pública de combate, restrito ou de maneira preponderante aos delitos graves e aos escolhidos inimigos da pátria.

Procurou-se com o estudo e a pesquisa, em primeiro, compreender melhor como o ser humano percebe o mundo ao seu redor e as consequências de seus atos em decorrência da ação ou omissão do Estado. Com o aprofundamento do estudo demonstrou-se, brevemente, um novel modelo de gestão para a área pautada, outra possibilidade e vertente, buscando harmonizar as sutilezas nacionais com a afamada teoria da janela quebrada, sem negligenciar aos direitos fundamentais e humanos, ampliando a cultura sobre o tema e posicionando de maneira mais adequada o Estado garantista.

Desta sorte, desgarrando de possíveis concepções equivocadas e preestabelecidas que reduzem a teoria e estudo ao simplório conceito separatista, alimentando o falso juízo de que os órgãos penais e policiais devem atuar como ingênuos instrumentos de acusação, a pesquisa elevou a escorreita cognição de que são elementos neutros e imparciais, que buscam verdades concretas e que almejam a prestação de serviços de qualidade, todavia, contemporaneamente, ao que parece, praticados com premissas desacertadas.

\section{DISCUSSÃO}

A violência urbana e crescente, não apenas em quantidade, mas, na qualidade de sua crueldade, certamente é para a população brasileira uma grave doença endêmica a ser combatida. O Estado brasileiro, de Direito e Democrático, deve ser pesquisado jurídico, social e filosoficamente, para apontamento de suas nuances e descoberta das fontes da origem de sua violência e sensação de impunidade, com diagnóstico que possa permitir um eficaz trabalho de gestão, adequando à realidade, consagrando o princípio da segurança jurídica, a ordem e, ao final, mostrar os reflexos na segurança pública e a queda de seus índices.

Contudo, o respeitado direito penal mínimo onde, em suma apertada, defende que a suposta truculência da consequência do direito penal não poderia autorizar a intervenção exagerada na vida dos indivíduos, devendo apenas ser considerada a última ratio de proteção ao bem jurídico, não pode preocupar-se com delitos de menor importância, ao que parece não deveria ser adotada como postura desmedida dos órgãos de segurança (FERRAJOLI, 2013).

Inclusive, é comum no meio jurídico a hermenêutica de documentos onde os representantes da advocacia, membros do Ministério Público e até mesmo Delegados de Polícia, nos casos de menor lesividade, representarem pelo afastamento da justa causa e posterior extinção do inquérito ou processo com base nesses princípios que atuariam na exclusão da tipicidade. Há várias decisões nos tribunais superiores que até mesmo pautaram os requisitos para a aplicabilidade. Todavia, o resultado obtido e amplamente divulgado em estatísticas e na sensação coletiva em nada possibilita uma conclusão favorável.

Aliás, o aumento incontestável da violência no Brasil, com delitos cada vez mais cruéis e sem pudor no descumprimento das normas vigentes, inclusive, com a sociedade e governos perdidos na busca da solução, conclamando medidas simbólicas como a diminuição de maioridade penal, recrudescimento das penas e aumento das leis, em verdade, tem relação direta com a atual escolha de gestão adotada para a segurança pública que é de predominância (na prática de exclusividade) no combate as ações criminais mais graves e, no campo oposto, com o fomento de atuação do direito penal mínimo, negligenciando a manutenção da ordem ou quanto aos pequenos delitos, com agentes estatais que ignoram a norma ou mesmo creem na revogação desta pelo costume enraizados.

Especificamente, a ideia desse estudo foi lançar que a relação de causalidade entre a desordem e a criminalidade é mais elevada do que entre a criminalidade e outros fatores sociais. 
Ainda, que se algo (fato) não tem importância ao Estado para dar justa causa em sua atuação acaba se tornando destrutível socialmente, com gravidade gradativa.

Entendemos que os atos de desordem e os delitos menores não devem ser ignorados apenas porque não causaram grande lesão ao bem jurídico. O que deve existir são qualificadas políticas públicas de prevenção e repressão a esses delitos menores. Não se defende a aplicação absoluta da pena privativa de liberdade. Na maior parte a prestação de serviço comunitário demonstra meio muito eficaz e que, certamente, norteia o mais importante que é a punibilidade de tais condutas e a presença do Estado.

Essa missiva, em verdade, visou um melhor entendimento sobre o possível abandono ao combate exclusivo do crime violento para a retomada da manutenção da ordem pública. À base principiológica da ação é a adequação para a realidade do país da teoria da "Janela Quebrada" (Broken Windows Theory) que surgiu a partir de um estudo realizado pelo cientista político James Wilson e o psicólogo criminologista George Kelling, ambos pesquisadores da Universidade de Haward, publicado em 1982 na revista The Atlantic Monthly, depois de um experimento, trabalho de campo, elaborado pelo americano Philip Zimbardo. O estudo teve por finalidade demonstrar a relação já citada de causalidade entre a desordem e a criminalidade (RUBIN, 2003).

No mesmo artigo científico exaltado continuou o autor:

Kelling e Wilson sustentavam que se uma janela de uma fábrica ou de um escritório fosse quebrada e não fosse imediatamente consertada, as pessoas que por ali passassem concluiriam que ninguém se importava com isso e que, naquela localidade, não havia autoridade responsável pelo manutenção da ordem. Em pouco tempo, algumas pessoas começariam a atirar pedras para quebrar as demais janelas ainda intactas. Logo, todas as janelas estariam quebradas. Agora, as pessoas que por ali passassem concluiriam que ninguém seria responsável por aquele prédio e tampouco pela rua em que se localizava o prédio. Iniciava-se, assim, a decadência da própria rua e daquela comunidade. A esta altura, apenas os desocupados, imprudentes, ou pessoas com tendências criminosas, sentir-se-iam à vontade para ter algum negócio ou mesmo morar na rua cuja decadência já era evidente. $O$ passo seguinte seria o abandono daquela localidade pelas pessoas de bem, deixando o bairro à mercê dos desordeiros. Pequenas desordens levariam a grandes desordens e, mais tarde, ao crime (RUBIN, 2003).

Outro experimento destacado para confirmar a tese anunciada foi executada pelo psicólogo americano Philip Zimbardo, que deixou um carro num bairro de classe alta na cidade de Palo Alto, Califórnia. Conforme o texto do artigo de AMANDA SOARES GOMES (2009), sobre a temática, "a primeira semana o carro permanecia intacto, entretanto após quebrar uma janela, passado poucas horas o automóvel estava totalmente danificado e roubado por grupos vândalos que por ali passavam".

Segundo os autores, caso se quebre uma janela de um prédio e imediatamente ela não seja consertada as pessoas que por ali passarem irão concluir que não existe autoridade responsável pela conservação da ordem naquela localidade. E logo todas as outras janelas serão quebradas. E em pouco tempo acontecerá a decadência da própria rua onde apenas as pessoas desocupadas ou aquelas com tendências para o crime irão se sentir bem naquele local, criando dessa forma um terreno propício para a 
criminalidade. Nos últimos trinta anos quando a criminalidade nos Estados Unidos atingia níveis altos que preocupavam a população americana e principalmente os responsáveis pela segurança pública, foi implementada um Política Criminal de Tolerância Zero que seguia os fundamentos da Teoria das janelas quebradas (GOMES, 2009).

A afamada teoria foi, segundo propagado na doutrina, a base para o bem sucedido programa conhecido como "Tolerância Zero" quando a cidade de Nova lorque, ao longo dos anos 70 e 80, com início motivado por desordens no metrô (transporte subterrâneo) teve índices alarmantes de violência. Todos os ilícitos eram repreendidos, inclusive, os de ínfima lesividade, "atitude esta tomada pelo Comissário da Polícia da cidade Willian Bratton. A ideia era exterminar todos os tipos de condutas criminosas, não havendo qualquer tipo de seletividade na atividade policial" (CÉSAR SILVA, 2015).

Os policiais americanos perceberam que as pessoas que pulavam as catracas, estavam armadas ou tinham mandados de prisão contra si, ou seja, dessa forma combatendo aquele delito menor evitou-se que aqueles que estavam armados praticassem outros crimes. É importante ressaltar que nem todos que cometem crimes menores necessariamente cometerão um crime grave, porém se não encontrarem alguma repressão, a tendência que se cometa um delito grave é maior (GOMES, 2009).

\section{CONCLUSÃO}

O estudo procurou demonstrar de maneira resumida a necessidade de modificação do modelo de gestão escolhido pelo Poder Público de combate exclusivo apenas a grande delinquência ou dos crimes bárbaros. Ainda, que os embriões dos criminosos graves são gerados, muitas vezes, pela ausência do Estado na pequena delinquência ou, certamente, no mau exemplo dos espectadores quando simplesmente abandona esta forma eficiente de prevenção.

Longe de clamar pela bandeira da massificação prisional, em verdade, a ideia singela pela reflexão e introdução do estudo acadêmico, é de apenas de rogar que o poder público possa sempre atuar de maneira comunitária, explicativa, educadora e presente, pois, a teoria acima, adequada as nossas realidades, auxiliaria em possível decréscimo da violência em prestígio ao aperfeiçoamento da cidadania e demais direitos consagrados.

\section{REFERÊNCIAS}

BRASIL. Constituição (1988). Constituição da República Federativa do Brasil. Promulgada em 5 de outubro de 1988. Disponível em: http://www.planalto.gov.br/ccivil 03/constituicao/constituicaocompilado.htm Acesso em 08 de agosto de 2017.

CÉSAR SILVA, Mateus Maciel. Teoria das janelas quebradas na Criminologia. Disponível em: https://jus.com.br/artigos/36275/teoria-das-janelas-quebradas-na-criminologia Acesso em 29 Jul.17.

FERRAJOLI, Luigi. Direito e Razão. 4a Ed. São Paulo: Revistas dos Tribunais, 2013. 
GOMES, Amanda Soares. Teoria das Janelas Quebradas. A desordem e a criminalidade. Disponível em: http://www.jefersonbotelho.com.br/teoria-das-janelas-quebradas-a-desordem-ea-criminalidade/ Acesso em 20 Jul.17.

RUBIN, Daniel Sperb. Janelas Quebradas, Tolerância Zero e Criminalidade. Disponível em: https://jus.com.br/artigos/3730/janelas-quebradas-tolerancia-zero-e-criminalidade Acesso em 24 Jul.17. 